Reluctant Leaders: An Analysis of Middle Managers' Perceptions of Leadership in Further Education in England

Denis Gleeson (Warwick) and David Knights (Keele).

Denis Gleeson is Professor of Education at the University of Warwick. His teaching and research interests are in the sociology of education, employment and the state and has published widely in the field. He has recently completed a number of research projects ( CEL,NASUWT,ESRC) looking at leadership, management and teaching and learning in further education, including research relating to academy schools.He is an editorial board member of 'The Sociological Review' and is a co-contributor to 'Improving Learning Cultures in Further Education'( Routledge 2007), based on the ESRC/TLRP Project, 'Transforming Learning Cultures in Further Education.'

Address.Warwick Institute of Education. University of Warwick. Coventry. CV4 7AL Email d.gleeson@warwick.ac.uk

David Knights is Professor of Organisational Analysis in the School of Economic and Management Studies at Keele University. He is a founding and continuing editor of the journal Gender, Work and Organisation and has published widely in the field of management and organization analysis. His most recent books are Organization and Innovation: Gurus Schemes and American Dreams, Open University Press, 2003 (with D. McCabe) and Introducing Organizational Behaviour and Management, London: Thomson Learning (with H. Willmott).

Mailing Address: School of Economics and Management Studies, Keele University, Staffordshire, ST5 5BG, UK. E-Mail: d.knights@mngt.keele.ac.uk 


\title{
Reluctant Leaders: An Analysis of Middle Managers' perceptions of leadership in Further Education in England. ${ }^{1}$
}

\begin{abstract}
The research that forms the basis for this paper draws attention to a group of middle managers who are reluctant to become leaders because they seek more space and autonomy to stay in touch with their subject, their students, and their own pedagogic values and identities, family commitments and the balance between work and life. This reluctance is reinforced by their scepticism that leadership in FE is becoming less hierarchical and more participative. In a sector that has had more than its fair share of reformist intervention, there is some scepticism of the latest fad of distributed and transformative leadership as a new panacea to cure all the accumulated 'ills' of Further Education in England. Although focused primarily on this one sector in an English context, the paper draws some inferences where there are parallels with wider sectors of public sector reform and where the uneasy (and incomplete) transitions from 'old' to 'new' public management have been underpinned by invasive audit, inspection and performance cultures.
\end{abstract}

Key words: Further Education (FE), Leadership, Professionalism, Power, Management.

Leadership is an elusive and hard to define concept. In this paper, we explore the meaning of leadership through the perceptions of a group of middle managers 'targeted' as potential leaders in the further education (FE) sector. Until recently further education has been described as the neglected 'middle child' of English education: a comparative low status due to its technical and vocational ethos has resulted in it being overshadowed by the policy priorities of schooling and higher education. However, in the past decade FE has expanded to become a significant driver for modernising the UK's learning and skills sector (LSS). In this process, considerable importance has been attached to leadership in FE, but despite this little is known about FE practitioners ${ }^{2}$ either as potential leaders or as those expected to implement changes in the sector.

The paper focuses on a group of middle managers who are reluctant to become leaders because they seek more space and autonomy to stay in touch with their subject, their students, and their own pedagogic values and identities - including opportunities to step outside existing practice. Such narratives challenge the view that leadership in FE is becoming less hierarchical and more participative, and raises questions as to whether fashionable notions of distributed and transformative leadership may simply mask a 'progressive' reworking of neo-liberal reform. This, we argue, is a major lacuna in the discourse of those who see leadership as the "new nirvana' for transforming troubled public sector organisations of which FE is arguably one of the most market tested in the UK context. Whilst focusing on one recurring strand of the data, the paper seeks to draw parallels with wider sectors of public sector reform where the uneasy( and incomplete) transitions from 'old' to 'new' public management have been underpinned by invasive audit, inspection and performance cultures. Treating FE as a 'case in point,' we seek to problematise current discourses of leadership from a critical sociological viewpoint. 
The paper is constructed as follows. In the first section, we provide a fairly brief examination of changing conceptions of leadership and its distinctiveness from management. The recent popularity of notions of leadership is seen as a function of the comparative failure of management working at a 'distance' to engage the enthusiasm, commitment and creativity of staff. Of course, leadership has been a focus for academics for several years but the domination of psychological and essentialist conceptions have rendered it often scientistic and abstracted from the context of everyday professional practice. The second section examines the relationship between leadership, management and professionalism in public sector education (FE). It focuses on the way that the essentialism of traditional mainstream leadership studies is continued. The sense of the leader as either a direct product of the characteristics of the person, the context, or of a mixture of the two (Grint 2000) is simply replaced by an essentialism of an inflexible, rule-based leadership in the past and an adaptable and customer-centric leadership in the future. This essentialism of the past and the future is not new since change agents always seek to demonise what they seek to replace but in so doing, tend to reproduce what they seek to discard (Spillane 2006). In practice, however, the life of public professionals is more complex and less dualistic than is portrayed (Gleeson and Knights 2006). Here we also discuss the practical problems faced by public institutions in recruiting and retaining leaders, preparing the way for the empirical narratives of the second section.

In the empirical accounts, practitioners display a number of concerns but rarely do these coalesce around any sort of consensus throughout the hierarchy. In a bid to repair the recent effects of managerialism on staff morale, recruitment and retention, senior managers tend to be convinced that one solution is to develop leaders from among the middle managers. However, staff display some resistance to this at least as a formal solution to the deeper issues. In a non-formal fashion, they often exhibit leadership in their routine everyday practices but these FE middle managers, and especially the women, seemed less enthusiastic about the responsibilities that would accompany career moves into formal leadership roles. In short, middle ranking professionals are often what we call reluctant leaders who, for a variety of reasons, are resistant to taking on positions higher up the hierarchy. Senior managers are also frequently sceptical of many of the fashions and fads emanating from Whitehall regarding leadership, values, and student-centred education but, at the same time, are aware that the Further Education sector needs to develop leaders (Merrick 2007). Insofar as this is the case, they assume that it is better to recruit from within the ranks where there is sound knowledge of educational practice.

In the final concluding section, we summarise the main findings of the empirical material and seek to locate them within the context of a discourse on the changing nature of professional leadership in the public sphere (Collinson, 2003; Fox, 2005). Overall the paper draws upon FE as a case that serves to problematize current discourses of leadership as the panacea for public sector ills. Through some of the narratives, it also raises certain gendered sensitivities in this preoccupation with leadership in the public professions, and suggests their implications for further research and analysis. Overall the paper is critical of much of the preoccupation with leadership both in academia and among practitioners but would not wish to throw the baby out with the bathwater since it recognises that organizations do benefit from the 
commitments of leaders. However, leadership has to be seen as an emergent feature of organizations and situated practices (Mintzberg and Waters 1985; Lave and Wenger 1991) rather than something that can be imposed on them (Grace 1995). It also should be acknowledged that it is frequently present in everyday routines even when no formal leadership responsibilities can be identified. Persuading middle managers to accept formal leadership roles can often disrupt the creative and innovative outcomes of such non-formal arrangements (Alexiadou 2001).

\section{Changing conceptions of leadership and management.}

In recent years there has been a revival in academic studies of leadership partly because of a parallel interest among practitioners. This practitioner interest could have a number of reasons some of which may simply relate to the historical cycle of fads and fashions and others that relate to the comparative failure of systems, markets or micro-electronic interventions designed to deliver on their promise to improve performance, productivity and professionalism in practitioner-client relations. A return, therefore, to human intervention was not long in gaining ground as practising managers recognised that managing systems or technology is easy compared to managing people if only because staff have to be encouraged, motivated, or inspired and cannot be guaranteed to comply with, let alone consent to, decisions from 'above' (Knights and Willmott 1999).

This current fascination with, and faith in, 'leadership' has been a vital ingredient in attempts to modernise public sector organisations that are often characterised as resistant to change. While such labelling can be contested, there is little doubt that it has provided fertile ground for a range of neo-liberal market reforms that have undermined the autonomy, and perhaps the confidence, of professionals in the public sector. Cultures of audit and accountability are routine yet very little is known about the practitioners (Foster, 2005) that are their target - who they are and how they interpret or seek to mediate and modify the changing conditions that constitute their professional practice. Similarly there is considerable energy and investment devoted to training leaders for the future, but little apparent understanding of how such leadership is contextualized in the everyday routines of public professional work. The dearth of research raises a number of questions concerning what constitutes leadership practice in this expanding but largely ignored $£ 10 \mathrm{bn}$. sector of public education (Hyland and Merrill 2003). One such question concerns the efficacy of hierarchies that separate off senior managers from middle managers and practitioners in contexts (e.g. teaching and learning; $14-19$ curriculum; personalised learning) that require more integrated or distributed leadership practices (Lumby 2005). Another relates to market positioning, governance and accountability of FE that affects both the survival of colleges and the way FE is understood more as a business than as an educational process (Lucas 2004). This failure to position leadership in the changing cultural and social conditions of professional practice is, we argue, a major challenge for those who believe that improved management and leadership is the 'new nirvana' for turning around a 'troubled' public sector (Blackler 2005).

The roots of this problem are many and diverse. At one level, it has been a function of academic research that has tended to psychologise leadership either as a cognitive 
property of persons or as a behavioural concept abstracted from empirical observation of its contextual conditions. Transactional leadership, for example, lacks any proper contextualisation since it presumes a performative and masculine-oriented culture, where leadership is largely about exchange relationships of instrumental reciprocity (Blau, 1964). It is expected to tie behaviour to the instrumental economic self-interest of individuals through rewards and punishments linked to performance targets and output (Burns, 1978; Bass, 1985).

This has been juxtaposed against transformational leadership the purpose of which extends beyond short-term instrumental interests and is designed to bring about organisational and service improvement through more reflexive and participative professional and stakeholder practices. Transformational leadership is sometimes associated with distributed or democratically devolved principles of shared responsibility, and team based, people oriented management (Handy, 1989; Bass, 1990; House, 1997). However, it also retains the more individualistic notion of transformations being stimulated by the charismatic, inspirational, intellectual or empathetic characteristics of the leader that are conducive to securing the respect of, and support from, followers (Knights and Willmott, 2007).

Conscious of the tendency for these abstracted distillations of practice to caricature what is more complex, relational and difficult to capture, we want in this paper to explore the possibility and plausibility of leadership within a more democratically accountable conception of professional practice. Understanding how professional cultures might act as significant precursors and preconditions for effective management and leadership does, however, require a leap of faith in terms of prevailing policy and academic discourse. As has been argued elsewhere, a largely command-led and behaviourist discourse has dominated recent public sector debate (Gleeson \& Knights, 2006), largely denying alternative ways of conceptualising 'the problem' of leadership in the public sphere. A more grounded approach is called for that has the advantage of avoiding dualistic thinking about 'top down' and 'bottom up' ways of understanding organisational change (ibid.), and the current preoccupation with an unreconstituted conception of leadership (Bottery 2004; Gunter 2005). One issue for which we believe our research has implications is the question of what might a community of leadership practice look like and how this could inform an understanding of democratic forms of leadership and management in the context of civic, rather than just market, accountability? (Woods 2005).

Recent research indicates that despite all the 'external' constraints limiting a response to this question, the potential for change being generated from within organisations is immense (Lave and Wenger 1991).So for example, both practitioners and students demand a voice in how organizations work refusing to have their experience at the sharp end disregarded in relation to pedagogy and changes in work design and organisation. They are also concerned that lifestyle change and transitions, identity, age and gender are fully acknowledged in relation to the expansion of education and learning opportunities (Deem and Ozga 2000; Gleeson 2001; Hoyle and Wallace 2005). There are a number of empirical accounts of the partly concealed creativity and innovative potential of staff \{e.g 'invisible trade' $\}$ in everyday practices within organizations (Kitchener 2000; Newman and Nutley 2003; Robson 2004; Gleeson 2005). However, the way that front line practitioners and public professionals mediate tensions between policy and practice in everyday situations with their clients, 
customers or students - through 'tacit knowledge' (Eraut 2000) or 'underground working' practices (James and Diment 2003) - have tended to be ignored in the field of management and leadership studies (Collinson and Collinson 2004; Fox 2005).

Hitherto, public professionals have often been portrayed as either the targets and victims of neo-liberal reform (e.g. audits, targets, quality controls, etc.) or as creative agents exploring and perhaps exploiting the contradictions of such reform through forms of 'resistance' or 'strategic compliance (Gleeson and Shain 1999; Bathmaker 2005). A common perception is that the 'problems' of leadership associated with such a polarisation are only likely to be resolved through focusing on the skills and expertise of followers - the workforce, and its ability to manage change rather than on the contradictory policies, funding arrangements, regulation, and stakeholder preferences that have 'captured the discourse' of everyday leadership practice. The tendency is for policy makers to believe that public professionals need to be more thoroughly inducted, managed and led in the ways to which the 'new' regimes of management truth aspire (Cabinet Office 2006; Miliband 2006).

In challenging the current assumptions of leadership, the paper explores some of the key issues through the narratives of an experienced group of professionals occupying middle-senior positions in the Further Education Sector (CEL 2005). As such we are less concerned here with the albeit important ways whereby public professionals resolve or reconcile tensions in their work than with illustrating how these tensions mediate the construction of professional habitus (Bourdieu 1980; 1990) and have significant implications for a practical and theoretical understanding of leadership as a a professional process (Lucas 2004). This approach contrasts with a prevailing managerialist perspective that seeks to impose new conceptions of Further Education (FE) professionalism whilst, at the same time, displaying little understanding of its practice or the neo-liberal assumptions that frame the conditions in which leaders and professionals work (Gleeson et al, 2005). Broader parallels that can be made with professionals working in other areas of public sector management are considered later in the paper.

\section{Leadership, Management and Professionalism}

What is the relationship between leadership and management? Often these terms are used interchangeably but an alternative is to suggest that the definition of the context in which they are to be applied invariably determines the approach (Gunter and Rayner 2007). So, for example, command approaches to leadership are invoked through constituting the situation as a crisis (Grint, 2005) providing the rationale for market and managerialist reforms to be initiated and imposed autocratically on the led. By contrast, the idea of management is invoked in situations that are constituted as stable since here established administrative routines are seen as important and more effective than dynamic leadership. Short-term solutions to problems are given precedence. Leadership proper is only invoked in relation to situations that are constituted as in need of long-term consideration and where innovative or unique solutions are demanded. This perspective represents a constitutive approach which avoids previous tendencies to treat the skills of leadership as either essential to the 
leader or determined by the context that he or she confronts - but sees both as constituted through social networks, involving the exercise of power, either individual or institutional. (Bottery 2004).

The ongoing transition from 'old' public administration (bureau professionalism) to 'new' public management (market choice), has involved perceiving public professionals as essentially steeped in bureaucracy and suffering from what Selznick (1957) described as 'trained incapacity', thus unable to adapt to changing market circumstances and customer demands. Equally essentialist, however, is the conception of the modernised reformed public professional who is driven by sensitivity to markets and clients as customers. This transition to new public management has radically redefined the relationship between leadership, management and professionalism (Dunleavy and Hood 1994; Clarke and Newman 2006)). While by no means complete, this transition involves the replacement of locally delivered systems of national provision, of services in education, health and welfare, by market levers based on contract, charter and consumer choice. Even though the nature of leadership, governance and accountability has shifted in this process, talk of the differences between 'public' and 'private' provision are generally over-exaggerated (Simmons et al, 2006). Here the past is demonised as essentially rule-driven and rigid whereas the future is romanticised as flexible and adaptable to changing circumstances and customers. An essentialism of the individual and the context is displaced only to reify the past and the future. One consequence of this is to ignore relational connections between the two and, in particular, how different forms of 'old' and 'new' systems of public management operate simultaneously in conditions of tension, contestation and negotiation.

Despite the UK's fascination with hard driven targets and heroic styles of management often fetishised in the private sector, the kind of leadership involved in running public sector institutions involves complex forms of governance and diverse power structures that are somewhat removed from conventional commercial and business operations (Caulkin, 2006). According to Simmons et al, (2006), public sector organisations operate in a constant state of flux in which competing notions of hierarchy, individualism, egalitarianism, enterprise and mutuality are mediated by leaders, managers and professionals at different levels. This involves leaders engaging with top down command and control policies (audit, funding, inspection, funding targets), responding to the plural demands of ambiguous producer, customer and consumer interests, and deciding how best to engage staff in actions that intersect so-called macro, meso and micro policy agendas. This process impacts on leadership and management styles in different ways not least in defining cultural values and beliefs that facilitate managing the tensions surrounding different modes of regulation, resistance, compliance, and conflict within the organisation. Increasingly, the art of leadership has become associated with transformational rather than transactional processes, involving the resolution of contradictions that both restrict and facilitate organisational room for manoeuvre. As leaders increasingly seek to overcome fragmentation generated by market dislocation and service failure, leadership has become imbued with 'new' doxas of distribution, professional reflexivity, networking and social partnership that address changing state-marketpublic choice agendas. However, underlying this new discourse the stark reality is that successful leadership in organisations is often a constant process of professional and practitioner renewal, bridging and brokering mismanagement, alienation and low 
staff morale, generated by market failure. In a recent study of leadership in FE, Lumby et al (2005) conclude that a mix of transactional, transformative, and distributed leadership is in operation.

"Though a transformational style is considered to be the most effective way to improve organisational performance, line managers are more often seen as employing transactional approaches. Distributed leadership is often distribution of operational responsibilities rather than a distribution of power.' ( Lumby et al 2005 p.1)

Leadership and governance have become highly complex if only because the context of their practice is uncertain and unstable due precisely to the recognition of the 'flexibility' of labour implied in such continuous processes of mediation ${ }^{3}$ and interpretation. Not surprisingly the shelf life of leaders can be relatively short, inducing a policy panic about their recruitment, training and retention. Policy initiatives in the setting up of specialised Academies and Centres for Leadership training in key areas of public sector provision, involving management consultants, senior sector personnel and leadership gurus, have only been partially successful in increasing the recruitment of potential leaders (Gunter 2001; 2005). Recent Whitehall concern about the reluctance on the part of middle ranking professionals to apply for leadership positions in areas of health, education and welfare has generated anxiety about where to recruit new leaders and why followers are so less than enthusiastic to make the step up to leadership (Barker, 2006/7; Collins 2006; House of Commons, 2006). The implication of this confirms Grint's (2005: 102) argument that there is a need to invert commonsense to recognise that followers have a lot to teach leaders about leadership.

One response from cash strapped and understaffed schools, universities, colleges, hospitals, health and welfare services is to adopt a strategy of 'growing your own' as a mechanism of grooming and fast-tracking those from the middle ground seen to possess leadership potential (Gleeson and James 2007). Though attempts to build sustainable leadership and professional capacity in this way is not new, it is based both on a fear of poaching and a recognition that organisational infrastructures have been diminished by long standing under-resourcing, casualisation and the negative effects of the audit culture and managerialism (Clow 2001). By investing in the professional and leadership development of middle managers, who operate at the interface of practitioner-senior managerial levels, it is envisaged that this strategy will enhance career ambition and participation, improve retention and provide the skills necessary for the transition into senior leadership positions (Simkins and Lumby 2003). Whilst there is evidence that this strategy, combined with staff release for management training programmes, is fast becoming the main route into senior management, it is by no means a universally endorsed career trajectory (Lumby 2005). If radical change and innovation is on the agenda, then many will argue for 'new blood' from outside, since existing staff usually have a predilection for maintaining the status quo. However, regardless of this objection there is the problem of some resistance among those existing staff 'in the middle' whose perceptions of leadership often suggest that it represents a risk to their professionalism and lifestyle balance that is not worth the trade (Gleeson and Shain 1999).

In the section that follows, based on the narratives from a recent study of Further Education ${ }^{4}$ supported by the Centre for Excellence in Leadership, we explore the 
perceptions of a group of experienced middle managers in response to recent reform in the sector. The study is based in four colleges in the midlands region of England. Its main focus of interest addresses a number of research questions, which though not inclusive include: Who are FE leaders and what are the professional values that define their practice? What leadership practices enhance or restrict improved communication, decision-making and collegiality among professionals at different levels of professional practice? What professional, learning and management skills do FE leaders of the future require? The colleges were selected on the basis of their size, location, scope and range of provision - inner city, urban, suburban and town situation - reflecting a cross section of FE colleges at national level. It draws on one hour taped interviews with 4 college principals and 28 senior, middle managers and lead professionals in the participating institutions. Additional data was generated through small group interviews, selective follow up telephone interviews and email contacts with participants, including feedback on various drafts of the interview data and final report. Additional data collected within the colleges included college development plans, corporation minutes, evaluation documents, external inspection and audit reports, and college data relating to professional development, staff mentoring and leadership training programmes. The study also derived benefit form one of the authors participating in two CEL leadership training sessions that involved focus group interviews with prospective leaders from a wider cross section of colleges. The research ,undertaken in 2006, coincided with publication of three major policy documents (Foster, 2005; DfES, 2006; Leitch 2006) -outlining radical reform of the FE sector - that provided a backdrop to the study in terms of the participants' perceptions of such reform on their work.

\section{A New Discourse of FE?}

Given the fast changing policy dynamic of reform in English further education and the impact this has on staff, it is as important to understand leadership from the perspective of 'followers', in this case middle managers, as from that of their leaders.(Grint 2005; Briggs 2005; Whelan et al 2006). In response to a combination of factors, ranging from policy neglect, mismanagement, low morale and recruitment issues, leadership is currently high on the policy agenda (DFES 2002; 2004; 2005; 2006). Improved leadership, learning and professional development, coupled with a closer realignment of further education with its employment related roots, is at the heart of Lord Foster's Review of Further Education - what he refers to as a 'new discourse' of FE (LSC 2005; Leitch 2006). In the first few years of the $21^{\text {st }}$ century, for example, there have been launched an unprecedented spate of policy initiatives (LSC 2005; DFES 2004; 2005; 2006;) advocating improvements in teacher education, workforce reform, 14-19 curriculum, professional development and leadership training. With an FE Bill currently before parliament and Government commitment to implementing both the Foster Review of FE (2005) and the Leitch Report on Skills,' 'Prosperity for All in the Global Economy-World Class Skills'(2006), FE looks set for major expansion with learning and leadership at its core (DFES 2006, our emphasis). However, according to two recent longitudinal research projects, which form part of the ESRC's Teaching and Learning Research Programme (Hodkinson et al 2005; Coffield et al 2006), the major thrust of FE reform is rhetorical and remains locked within a restricted audit and target driven framework: 
"Pressure to improve teaching, learning and management in FE are primarily externally driven by concerns other than the nature of teaching and learning.... Learning in FE is pressurised and destabilised by a combination of inadequate and unstable funding and a rigid audit regime, focused on targets, achievement and OFSTED inspection standards. Over the last 50 years, there have been repeated calls for the improvement of teaching and learning in FE to solve perceived social and moral problems among youth; insufficient skill levels to ensure the nation's global competitiveness; and the need for a cost-effective FE service. Beneath these different calls for improvement, lies a basic problem - the demand that the sector provides effective responses to some of the country's major social, employment and economic needs, but with everdecreasing resources" (Hodkinson et al 2005. p7).

Rather than address such issues head on, the Foster Review (2005) and the subsequent FE White Paper (DfES, 2006) have focused heavily on leadership as its great 'big hope'. The key policy issue underpinning both official documents is the attempt to create 'a new discourse of FE' that privileges closer economic partnerships between business, employers and colleges. Central to this vision of FE's historic mission (as the 'handmaiden' of British industry) is the need to establish a new generation of leaders who are able to:

- think strategically, creatively and systematically;

- promote a student and employer centred vision that delivers the central purpose;

- manage and lead the FE college, based on a stronger set of organisational values and with the full engagement of staff in the core mission and purpose;

- constantly scan the environment and policy agenda, anticipate change and innovate to meet its needs.

(Foster, 2005, p3-4)

Against the background of FE gearing up to its 'new' core mission, the following narratives indicate the perspectives of experienced FE middle managers in the changing context of their work (CEL, 2005). A recurring theme in the narratives explored here is that while their perceptions of what is important in the successful management of FE differ, the 'new discourse 'of leadership does not necessarily sit well with the values to which middle managers subscribe(Barker 2006). However, in contrast to research that emphasises the divisive and 'deprofessionalising' effects of managerialism on relations between senior managers and practitioners - with middle managers 'brokering' conflict between the two - the data in this study indicates a more nuanced understanding of 'resistance and compliance,' around issues of worklife balance and professional values (Randle and Brady 1997; Gleeson and Shain 1999; Briggs 2005). Whilst the nature and interpretation of such values remain keenly contested, there are tensions and trade-offs involved in balancing professional and pedagogic judgements alongside the business of FE (Ainley and Bailey 1997; Colley et al 2006). Echoing earlier parts of our analysis Rob sets the scene for what follows, arguing that leadership comes from within.....

"New leaders come from within....you have to grow your own stock....FE had to do this as it's been neglected by government. Working in education means professionals have to have technical or subject expertise as well as business 
acumen and people driven skills. The idea that you can transplant a Business Practice Model easily into FE is misguided....business leaders who come into FE and want to work on those principles can't get their head around everything that goes on in FE ...the constant audit, inspection, funding contradictions.... this inhibits a lot of existing practice.' (Rob. Faculty Head).

In many respects Ron's account anticipates some of the key issues discussed here. While his notion of leaders being nurtured 'from within' (Gleeson 2006)can be interpreted in different ways, it is not particularly new. 'Organic' development, of course, has pragmatic appeal to policy makers, leaders and senior managers anxious to develop their staff, but this does not necessarily accord with the views of those in receipt of such targeting, as we go onto argue.

\section{'Growing Your Own'}

Renewed interest in 'growing your own' leaders from within is influenced by a number of factors. As Ron notes these largely relate to a neglect of the sector that has resulted in staffing problems, including high turnover at all levels, difficulties in attracting staff, and the employment of casual staff (see Collinson 2006). Despite limited resources the colleges involved in this study established a number of strategies designed to address such neglect, including mentoring, shadowing, peer observation, F/HE partnerships, the appointment of advanced practitioners and senior staff responsible for professional and career development. This approach, combined with developing college consortia, consultancy and external training programmes has raised the profile of leadership planning in FE significantly (CEL 2005). However, compared with school and HE, health, welfare, children's services and social justice systems, the level of funding available for such investment in FE remains limited with knock on effects for career development of middle managers (Briggs 2005: Whelan et al 2206; Barker 2006). Beneath this tier less than fifty percent of practising FE lecturers have received initial teacher education and more than forty percent are on fixed term or part-time contracts (House of Commons, 2006).

'Growing your own' is a practical internal response to the problems faced by FE Chief Executives and senior managers who have found it impossible to recruit leaders externally because of the restricted audit and resource limits placed on FE.. This has increased levels of tension in colleges surrounding training up new and existing staff that are then tempted to move on or away because of a fractured and poorly resourced working environment ${ }^{5}$. Another limitation of perhaps more importance, however, concerns the position of existing lead practitioners and middle managers in FE who are increasingly seen as the recruiting ground for future leaders (Gleeson and Knights, 2006). Our research reveals the potential but also the severe constraints in seeking to plug the leadership gap through building a career structure for middle managers in FE. A common feature of professional workers such as teachers is that they are dedicated to the activity (e.g. pedagogy) for which they entered the profession and thereby seek to avoid work (e.g. management) that takes them away from it (Ainley and Bailey 1997).

"one minute you're a teacher in the classroom....and the next minute you're a middle manager...(John, Head of School). 
"am I leader what ever that is....you fall into it. I was once a teacher. You stick your head over the parapet and you get sucked in....Oh, you're good at that and you move up and you're recognised as good at something..... and you get more to do...(Joe, Faculty Head)."

"I started out as a lecturer and have since become a programme manager....a middle manager post. It's a manager post that's not clear to me. The previous incumbent was a senior manager and [had] more pay and responsibilities. I am responsible for the programme but not the staff. Someone else has that responsibility ...." (Anne, Programme Manager).

"I want FE to recognise good teaching and learning and keep the best teachers where they are and reward them....not pushing them up the ladder into middle management roles to plug gaps..." (Alison, Head of School).

While middle managers such as John, Joe, Anne and Alison are increasingly being targeted as future leaders there are a number of unexplored issues surrounding this strategy - one of which is how they actually perceive leadership. Middle managers do not constitute a homogenous group and their career movement is often unplanned and involves subtle brokering skills between practitioners and senior managers. Issues of identity underpinning the in-between or 'go-between' status of middle managers can also generate counter-reactions to climbing the greasy pole (Gleeson and Shain, 1999). If being caught in the middle is one such ambiguity another concerns the risks and insecurities of investing one's self in a future that lacks any recognised sense of career. To be meaningful, of course, a career has to be seen as offering something that recognises and rewards skill, endeavour and sacrifices made with respect to other aspects of life (e.g. family, leisure) and professional work (e.g. pedagogic beliefs, political values). The narratives from the research, however, place a question mark over assuming that the rewards of career compensate adequately for the sacrifices.

"I carry different hats. In college I'm a middle manager, but working with employers I'm a senior manager (Mary, Head of Business Partnership).

"As a Head of School you get it from above and below....there's often stress about missing targets that we don't know about or (that) have changed at the last minute....is it LSC's (Learning \& Skills Council) fault or ours? Sometimes even senior colleagues don't feel they are being developed....it's often only if and when new spaces open up....so I do this kind of work for my colleagues...." (Jean, Head of School).

"I'm not an assertive person so I don't see myself in a very senior management position. I need to feel that I can put my skills to good use....not pushing paper around....my ambitions are about branching out not just going up the ladder....being a professional isn't just about delivery, delivery, delivery...." (Alison, Programme Leader).

"Is the next step up in the current climate....there are doubts about this FE climate....or should I move to another college. I'm questioning what I want to do. In the past I'd have the answer....but not now.... I'm not sure if I went 
upwards where I would find myself....in a difficult situation which might run counter to my education beliefs. When I hear my senior colleagues talking about invisible numbers....losing courses, battles with the LSC.... when all I can see is the value of widening participation. It makes me think...." (June, Head of Quality).

Thus not only do middle managers such as Mary, Jean, Alison and June wear different hats and 'get it' from above and below, they often occupy senior roles that, in some cases, have been downgraded from a previous era. In other words, middle managers' work practices can be significantly more complex, innovative and 'senior' than their designation implies. While this holds appeal to many middle managers in their everyday working practices (Collinson 2006), it can also result in tension and disenchantment should no further recognition or professional development follow. As the narratives ventured further into this territory, the significance of gender and identity as 'normalising' and yet also challenging of conventional conceptions of FE became more apparent.

While the number of women FE principals has increased significantly in recent years their numbers, overall, remain small compared with men. This study involved two women principals and a significant number of women in middle and senior management roles (15 of 32+ participants interviewed). Yet despite the apparent 'feminisation' of FE, notably in the middle ranks, women expressed mixed views about their prospects (Hughes, 2000). Their concerns focus on a number of issues relating to 'going up the ladder' or 'branching out'. Caution is expressed about the absence of any proper career structure and how the 'gaps' and 'opportunities' on offer can 'sideline you from your real professional interests' (Clow 2001). Sometimes these interests are the professional commitment to teaching but often there is a concern to protect a way of life, family commitments and even their very gender from the contamination of over-demanding, often pseudo management functions and tasks (Shain, 2000). Given that these functions frequently demand working beyond the call of duty and are rarely fully acknowledged or rewarded formally (the 'blind eye') but merely carry with them a tacit promise of future career development (Kerfoot and Knights, 1993), it is not surprising to find a high degree of scepticism especially among women managers. Of course, such informal career structures where the criteria for development are kept vague can be a form of indirect sex discrimination ${ }^{6}$ since women often may be unable to comply with the extra-curricula demands in the same way as men (MacDonald et al., 2005). At the same time informality, vagueness and invisibility may create spaces in which middle managers, of either gender, can ply their 'brokering skills' until such time, as Gleeson and James (2007) note, the rules change. However, there is another downside to informality for it deprives these middle managers of any resort to grievance procedures since they are not officially carrying out these duties in the eyes of the college.

Informality is, therefore, a way of allowing senior management to exercise power and patronage beyond that which is embedded in a specific job specification.. However, the interface between formality and informality in the workplace is not so clear-cut. Mary, for example, recognises this when she questions the term of 'multi-tasking' as a convenient label attached to the perceived generic skills of women. Jean on the other hand, is ambivalent about leaving her subject area and concerned that promotion 
might 'de-feminise' her. Helen is rather more ambitious but regrets the absence of a clear career structure and how easy it is, through filling gaps, to get sidelined into middle management. Margaret expresses the fear of extra workplace demands threatening commitments to her family. For Karen, 'Leadership' is not about gender or style but about power.... The proper use of it....it's ethical leadership that matters'.

"I'm pretty gender aware and from a working class background. The idea that women make better managers because they can multi-task - I'm not sure about that. Or is it about spaces open up for them and it becomes a way of women dealing with perceptions of themselves that become a handy label....I feel that FE promotes its staff in terms of gaps and crises [rather] than through developing individuals....it may be that women have more of a sense of duty or guilt about things. I know I can't multi task....but maybe all professionals in FE, men and women, could develop a range of skills through professional and personal development, acting in modular ways, working across areas and in teams even taking sabbaticals..." (Mary, Head of School).

"I am conscious of the need to move on and up in FE....as I'm being encouraged to do....but it means leaving my subject area.... I'm keen to further my career....thinking of going up the tree....but I'm not sure about the skills needed....I don't want to de-feminise myself...." (Jean, Head of Section).

"I want to stay in FE....being a principal is a bit ambitious....perhaps as an Assistant Principal maybe in a cross college role.... around quality and standards.... As you get higher up the ladder in FE you get judged more and it's tougher....women never think they are good enough....the other thing is that there are no career paths in FE...the old gradings have gone....it now provides openings through gaps and opportunities....most people come into FE as teachers from employment and don't see themselves developing in senior management....though many get sidelined into middle management through new opportunities and staff shortages...." (Helen, Programme Leader).

"Sometimes I feel that if I had the extra hours at work to 'grease the engine' dealing with the unknown....to stay on a while and complete everything - but then I already do that and miss $1 \frac{1}{2}$ hours each day with the children....my mother looks after them, mixing and matching!" (Margaret, Head of School).

"I'm fed up with all the talk about leadership....women (on courses) being told how to manage structures and systems....getting the right people on the bus. Leadership is not about gender or style but about power....the proper use of it....it's ethical leadership that matters ..." (Karen, Assistant Principal).

These narratives reflect some of the most significant challenges to so called succession planning for leadership in the context of professional work and not just in FE. There are strong parallels with research involving health care workers, medics, nurses, social and welfare workers that bear on recruitment, career development, and 
professional issues in the wider public sector (Caulkin, 2006; Simmons et al, 2006). Intense internal and external pressures on FE generate conditions that hide an 'extra hours' culture in which middle managers plug gaps in provision and resources, take on additional duties and engage in underground working practices to get things done, over and above their contractual duties (Gleeson 2006). If this is the price of apprenticeship into leadership it has its downside. Often this reservoir of expertise, altruism and professionalism passes unrecognised and can deter middle managers from furthering their careers. As the narratives in this section suggest, middle managers seek more space and autonomy, a more expansive working environment, opportunities to stay in touch with their subjects (disciplines and students ${ }^{7}$ ), and their own pedagogic values and identities - including opportunities to step outside existing practice (branching out rather than going up the tree) and engage in reflexive thinking about teaching and learning. Such thinking has implications for understanding and reworking the middle tier of FE as the future training ground of its leaders. In particular, it challenges the view that leadership is becoming less hierarchical and more participative, and whether the appearance of engagement is not simply a smokescreen to dissemble what is an underlying reworking of neo-liberal reform.

Whether real or imagined, in this study middle managers' perceptions of leadership as compromising their educational beliefs, engaging with bureaucracy, or losing contact with their femininity, says more about the substance of leadership than just its 'style' (Deem and Ozga 2000; Gleeson 2001). In gendered terms this can affect leaders' perceptions of eligible leadership material coming through the middle ranks - as not resilient enough or up to the job (CRE 1999; CEL 2005). Procedures designed to select, groom or nurture prospective leaders may unintentionally reinforce such perceptions that restrict distributed leadership and career progression among women, black and ethnic minority staff (Osler, 1997; Scott \& Lawson, 1997; Foster, 2005). Equally, such hidden practices draw attention to the overall lack of a coherent career structure in a sector that has more to do with plugging gaps and filling holes than developing FE's workforce and promoting equal opportunities (Lucas, 2004). In the final section we consider some of the wider implications of this for understanding leadership as a 'managed professional process' in the changing context of public sector reform (Audit Commission 2002).

\section{Leadership under new public management}

We began this article by suggesting that leadership in FE is an elusive and hard to define concept best understood in the context of the professionals who constitute its practice. In place of evidence based research of the kind we have attempted - albeit in a limited fashion - policy in the guise of New Public Management has tended to impose the idea of leadership on a workforce that has already grown tired of fashionable managerialist interventions (Grace 1995; Gunter 2005; Pollitt 2003). Ironically the attraction to leadership as a managerial device has arisen because various system intervention devices have failed to deliver what they promised (Bottery 2004). Hence there is the appeal of and to the human dimension in the idea of leadership. Unfortunately, rarely are earlier approaches to leadership sensitive to the practices of professionals in the contexts of their everyday lives (Hoyle and Wallace 2005). Nor are they generally aware of the gendered character of 
management strategies (c.f. Sinclair, 1998; Sinclair and Wilson, 2002) in invoking barely visible pedagogies of power through appropriating the goodwill and free labour of staff and of securing informal modes of leadership on the cheap. For many of our women respondents were exhibiting high-level mediation skills that were neither recognised formally as leadership nor thereby rewarded (Kerfoot and Knights, 1993). Although not formally recognised as leaders, our respondents displayed many of the attributes of 'shared leadership' as depicted by Pearce and Conger (2003 p. 2):

'Depending on the demands of the moment, individuals who are not appointed as formal leaders can rise to the occasion to exhibit leadership and step back, at other times, to allow others to lead'.

At the same time, however, the experience of extra-curricula activities that management identified as informal training for leadership served to disillusion many of the staff about the benefits of accepting formal promotion. Despite demonstrating the ability and skill to take on leadership roles, they became reluctant to do so because of the sacrifices that would be necessary in relation to issues of work-life balance and the potential threat to personal, professional and pedagogic values.

While the most recent academic literature on leadership has departed from traditional conceptions of perceiving leadership in terms of individual characteristics or of adaptation to the contextual contingencies in which it occurs - in favour of a more constitutive approach - leaders themselves continue to see it more rigidly. Evidence suggests that they tend to believe in a heroic conception of leadership where it is something that must show through when individuals are put under pressure (Roper 1994; Sinclair 1998; Sinclair and Wilson, 2002). Senior managers demanding extra curricula work from staff in order to test out their leadership skills before offering them formal positions reinforce this. Again the heroic view prevails and leaders can only prove their qualification for leadership by showing individual resilience, selfreliance and an ability to thrive on pressure and work intensification (Eveline, 2004; Binns, 2005) The heroic vision of leadership also presumes that most individuals are ambitious to climb hierarchies as a means of securing material and symbolic success (Kerfoot and Knights, 1996). While such assumptions cannot be dismissed, there is some evidence in our data that they need to be significantly qualified. However, it is unlikely that the staff interviewed were inherently lacking ambition so much as had become disillusioned by the 'tests' of leadership that subordinated all other values and interests to its heroic mission. Leadership of this kind is about sacrifice of personal, professional and familial values that many are unprepared to accept on these terms.

The experience of masculine definitions of leadership in practice convinced a number of potential leaders and especially women that this was not worth the trade in terms of how they wished to live their lives. Ironically, such modes of leadership are not only incompatible with civic values but also with the demands of the modern organization (Deem and Ozga 2000; Shain 2000; Fletcher, 2002; Pearce and Conger, 2003; Eveline 2004). Where change, diversity and flexibility are in evidence, sensitivity to difference in staff and clients or customers is important, whether it is an FE college or major corporation (Audit Commission 2002; CRE 1999 Commission for Black Staff in Further Education 2002). Leadership in these circumstances probably requires the very opposite of individual and competitive heroism - greater degrees of collective empathy, social interaction, cooperation and collaboration (Fletcher, 2002; Binns, 
2005). However, the heroic ideal is not without its tensions and propensity to disintegrate, embedded as it is in inherently precarious masculine identities and discourses (Kerfoot and Knights, 1993;Binns, 2005). Moreover, if FE is to recover from the present impasse with regard to leadership, the implication of this research confirms Grint's (2005: 102) argument that we need to invert commonsense to recognise that followers have a lot to teach leaders about leadership (Collinson and Collinson 2005).

Are there implications of this analysis of FE for other spheres of the public sector and indeed are there some meaningful comparisons that can be made with other areas of management and organization? Comparative analysis of the effects of managerial reform on professionals working across a range of public sector provision (probation, school teaching, hospitals, welfare) suggests two contradictory processes going on. The first shows a high incidence of unintended consequences, ambiguity and wasted effort resulting in fatigue, low morale and deprofessionalisation (Newman and Nutley 2003). The second reveals innovative skills and practices being constructed by professionals 'in and against the audit culture' on the ground (Stronach 2002). Such practices, involving brokerage and mediation skills, often require professionals mediating contradictory policy-practice agendas at the interface of their everyday practice. These process have been variously described in recent research as 'underground working', 'hidden trade,' 'restorying identity,' 'tacit knowledge', 'principled infidelity,' 'conscientious objection' and 'added value,' as ways in which professionals both seek to sustain a sense of meaning, identity and autonomy their lives as well as getting the job done (see for example James and Diment 2003; Kitchener 2000; Stronach 2002;Eraut 2000; Hoyle and Wallace 2005;Colley 2006; Robson2004). Such knowledge by its nature is invisible -often seen by politicians, policy makers and media 'as part of the problem' - and passes by largely unrecognised as legitimate professional and leadership knowledge in the work place. At the same time it is the stuff by which organisational work get done and is, as we have argued, also associated with both innovative and reproductive practices.

We are aware of the dangers in drawing too close a parallel between FE and wider public sector organisations for a number of reasons. One is that hospitals, welfare offices, health centres, schools, universities, civic offices and courts all operate in different organisational cultures and market settlements, including diverse relations of power with key stakeholders. Even within recognised occupational categories such as nurse, doctor, teacher, lecturer, civil servant, social worker, legal adviser and health practitioner, there are many sub categories of hierarchy, expertise and practice that defy easy comparison. Yet despite such diversity, recent research has focused on the way public policy is being reworked at the level of practice - whether by design or default - in the void generated by 'failures' of both old and new public management regimes (Farrell et al 1999; Hood and Peters 2004, Simmons 2006). On the ground it has been left to practitioners and managers - albeit held to account by their 'licensed autonomy- to broker and interpret contradictory policy messages that, on the one hand, embrace notions of enterprise, consumer and public choice whilst, on the other, impose restrictive funding, audit and inspection mechanisms that limit their room to meet defined targets (Clarke and Newman 2006).

Though the meaning of such concepts as 'enterprise' and 'public choice' are ambiguous and generate different reaction and response (e.g whose choice?), they 
convey powerful signals of central control over the funding, provision and delivery of public services at an organisational level (Hendriksson et al 2006). In a so-called post neo-liberal market state, these benchmarks increasingly define the detailed delivery of new public management to be interpreted by leaders whose organisations and staff will be measured, audited, inspected and funded on the basis of their ability to deliver on these policy principles (Benson et al 2001). In the context of such 'new' market principles notions of learning, leadership and professional practice are becoming more complex and nuanced than earlier conceptions of 'proletarianisation' and 'deprofessionalisation' suggest (Randle and Brady 1997). Increasingly public service delivery is being brokered, mediated and reconstituted by professionals in highly volatile situations, in conditions where the identity and, in Ball's (2003) terms, the soul of the professional is at stake (Collinson 2003). In this sense the complexity of FE as, ' a case in point', though different from a school, hospital health centre, clinic or welfare office, operates along parallel lines of power, accountability and control that simultaneously restrict and enhance professional room for manoeuvre.

\section{Conclusion}

We believe that these and broader research findings on professional work and leadership challenge prevailing public sector workforce reform that is focused primarily on accountability, audit, inspection and control. This is because these formal controls fail to engage professionals in ways that enrol their commitment and goodwill, and mobilise their willing expertise. Such transformations could be accomplished were the public sector to recognise formally the value of shared leadership (Pearce and Conger, 2003) rather than to remain trapped in practices that reflect and reinforce heroic conceptions leadership. In terms of the comparisons of the limited findings of this study for management and organization more generally, it might be argued that the formal appropriation of invisible labour in the public sector is not the answer. The plugging gap mentality and the expectations of working beyond the call of duty in FE resembles some of this demand on the goodwill of staff to deliver well in excess of their statutory obligations and the system of formal rewards. An additional feature of our study of FE relates to how middle managers do not necessarily see themselves as leaders but as professionals. (Collinson 2003). More precisely, by focusing on its manifestation in the 'corporate culture' of FE, we have sought to show how the concept of leadership should not be taken for granted. The staff interviewed here are not continually seeking promotion especially when it involves a threat to their pedagogic values, work-life balance, or defeminisation in order to comply with heroic notions of work pressure and intensification. At the same time, they do express alternative conceptions of leadership that refuse the implication of sacrificing life to work (Bathmaker 2006). Insofar as these alternatives seem not to be on the formal organizational agenda in FE, 'growing their own' may prove not to be the solution anticipated by senior managers to their leadership problems.

Part of this can be interpreted as the way in which demand and control strategies associated with audit, inspection and performance management not only normalises hierarchy and difference ( e.g CEO, leader, senior manager, middle manager and practitioner) but also encourages organisations to 'save the hierarchy' (Blackler 2005), thereby distracting professionals from the core purpose of their work in improving, in this case, teaching and learning in FE. This points to the inadequacy of performative arrangements that separate off leadership and management from their 
professional mandate. This not only ties the hands of participants concerned but it also restricts shared experience, teamwork and effective delivery of public services in direct contradiction of the expressed rationale of market reform to more flexibly meet diverse client need. Depending on which position you take, this draws attention to the simultaneous ways in which public professionals participate in contested forms of social and gendered reproduction that both challenge and reinforce its legitimacy. At the same time, it exposes fault lines in current discourse that ignores the nature of leadership as a professional activity rooted in civic society and not just in the market. In the current context the key issues confronting professionalism (managerialism, audit, inspection, targets and performance management) involve conflict and struggle rather than consensus and trust. Debate needs to extend beyond matters to do simply with leadership and management to issues that are rooted in deeper forms of power, governance and accountability necessary to promote democratic professionalism in and for civic society (Marquand 2000). As we have argued elsewhere, (Gleeson and Knights 2006) this brings into sharp relief the bigger picture of regime change that is required to bring underground working practices and professional voice in from the cold. This embraces recognition that the professional imagination resides in forms of democratic governance and not just unaccountable audit and managerial cultures that lack the embodiment and internally developed legitimacy necessary to engage real professional commitment. For the latter are comparatively immune to professional and democratic accountability as they reflect and reinforce a rigid and routinized set of procedures for protecting institutions rather than advancing civic responsibility. This is about promoting practices that are accountable not just in terms of the market and audit but also socially through a more vibrant democratic, civic society reflecting the ethical virtues of professional responsibility to citizens and the community in what might be seen as an "inexhaustive care for the other" (Knights and O'Leary 2006: 134).

For all professionals civic society and citizenship are more demanding of them than has ever been the case historically, not least because of higher expectations of knowledge, participation, and service. No longer can professional expertise trade on exclusivity and distance. There is a demand for inclusion and a demystification of knowledge. In such circumstances, professional leaders manage not at a distance and by demonstrating difference or superiority over followers but by bonding and engaging with them in pursuit of common goals and shared values. They also have to work with their clients or customers by sharing rather than imposing knowledge and expertise. In the long run this may mean that clients and customers become more capable of self-management and are thus less demanding or reliant on professionals (Pearce and Conger 2003). However, such a scenario is perhaps beyond the horizon of even those organizations on the frontiers of change let alone public sector institutions that have tended to be followers rather than innovators. Nonetheless, our paper suggests that it is time for a rethink about leadership in the public sector if professional provision of services is to keep pace with the increasing and diverse demands of their publics in privatised contexts.

\section{References}

Alexiadou, N. (2001) Management Identities in Transition: A Case Study in Further Education,' Sociological Review. 49(3): $412-435$. 
Ainley,P and Bailey, B ( 1997) The Business of Learning in Further Education. London Cassell.

Audit Commission (20020 Equality and Diversity. London;Audit Commission.

Ball, S (2003) 'The Teacher's Souls and the Terrors of Perfomativity,' Journal of Education Policy 8(2): 215-228.

Barker,P (2006/7) Succession Planning for Middle Managers.pp 95 -107 in Collinson, D (Ed) (2006/7) Research in Leadership in the Learning and Skills Sector: By the Sector,On the Sector, For the Sector. Centre for Excellence in Leadership. Lancaster University.

Bass, B. M. (1985). Leadership and performance beyond expectation. New York: Free Press.

Bass, B. M. (1990). From transactional to transformational leadership: Learning to share the vision. Organizational Dynamics, (Winter): 19-31.

Bathmaker, A-M (2006) Alternative Futures: professional, identity formation in English Further Education in Satterwaite, J, Martin W, Roberts, L (2006) Discourse, Resistance and Identity Formation. Trentham Books. Stoke-on Trent.

Benson, L, Bruce, A, and Forbes,T (2001) 'From Competition to Collaboration in the Delivery of Healthcare. Journal of Nursing and Management 9,pp 213-220

Bennis, W. G and Nanus B (1985) Leaders: The Strategies of Taking Charge, New York: Harper \& Row.

Binns J (2005) 'Diversifying Leadership Discourse: Heroic \& Relational Leaders: a Gendered Dialogue’, http://www.chloe.uwa.edu.au/page/79434 Consulted 03/04/2007.

Blackler, F ( 2005) Chief Executives and the Modernisation of the English National Health Service. Leadership. Vol 2(1) 5-30.

Blake, R R, Mouton, J S (1964) The Managerial Grid, Houston, Texas: Gulf Publishing

Blau, P. M. 1964 (1964) Exchange and Power in Social Life. New York: Wiley.

Bottery,M (2004) The Challenges of Educational Leadership. Sage

Bourdieu, P (1998) Practical Reason. Polity Press, Cambridge

Briggs,ARJ (2005) Middle Managers in Further Education Coleges:the new professionals. Journal of Educational Administration. 42(5) 586-600

Bryman, A (1986) Leadership and Organization, London: Routledge \& Kegan Paul.

Burns, J. M. (1978). Leadership. New York: Harper \& Row.

Caulkin, , (2006) Forget about targets and decide what really matters. The Observer, 23/04/06, p8

Cabinet Office (2006) The Government's Approach to Public Sector Reform Prime Minister's Strategy Unit London.

Clarke, J and Newman, J. (2006) The Rise of the Citizen Consumer: Implications for Public Service Professionals. www.open.ac.uk/social sciences/citizen consumers

Coffield F (2000) The Necessity of Informal Learning, Bristol Policy Press. 
Coffield, F. Steer, R. Hodgson, A. Edward, S and Finlay,Y. (2005) A New Learning and Skills Landscape? The Central Role of The Learning and Skills Council. Journal of Education Policy 20(5) 631-656

Colley, H. James,D and Diment,K (2006) Unbecoming Teachers: Towards a more dynamic notion of professional participation. Journal of Education Policy. 22(3) 173-193

Colinson, D (Ed) Researching Leadership in the Learning and Skills Sector: By the Sector,On the Sector,For the Sector.Vol 1. Centre for Excellence in Leadership. Lnacatser University.

Colley H., Hodkinson, P and Malcolm, J (2003) Informality and Formality in Learning, London: LSRC.

CEL (2005) Career Paths: How individuals make it to the top in the Learning and Skills Sector. Centre for Excellence in Leadership, Lancaster University

Clow,R. (2001) 'Further Education Teachers Constructions of Professionalism.' Journal of Vocational Education and Training, 53 (3) 407-419.

Collinson, D (2003) Identities and Insecurities: Selves at work. Organisation 10 (3) pp 527 - 547

Collinson,C and Collinson,D. (2005) Leadership Challenges Centre for Excellence in Leadership, Lancaster University.

Collinson, D (Ed) (2006/7) Research in Leadership in the Learning and Skills Sector: By the Sector,On the Sector, For the Sector. Centre for Excellence in Leadership. Lancaster University.

Collinson, D (2006) 'Appeal of the roller coaster job.' Times Educational Supplement . August p30.

Commission for Black Staff in Further Education(2002) Challenging Racism: Further Education Showing the Way. Commission for Black Staff in Further Education.

CRE (1999) The Leadership Challenge: Progress Report. Commission for Racial Equality at www.cre.gov.uk/

Deem, R and Ozga,J.(2000)' Transforming Post Compulsory Education? Femocrats at work in the academy.' Womens Studies International Forum 23 (2) 153-166

Collinson,D (2006) Rethinking Followership.A post-structural analysis of follower identities. The Leadership Quarterly. 17(2). 172-189.

DfES (2002) Success for All: Reforming Further Education and Training. White Paper

DfES (2004) Equipping our teachers for the future: Reforming Initial Teacher Education for the Learning and Skills Sector. HMSO

DfES (2005) 14-19: Education and Skills. HMSO.

DfES (2006) Raising Skills and Improving Life Chances. White Paper, HMSO, London

Dunleavy,P and Hood,C. (1994) From Old Public-Administration to New Public Management, Public Money and Management, 14 (3), pp 9-16

Eraut,M (2000) Non Formal Learning: Implicit learning and tacit knowledge, in Coffield,F (ed) The Necessity of Informal Learning.. Bristol.Policy Press.

Eveline, J. (2004) Ivory Basement Leadership: Power and Invisibility in the Changing University, University of Western Australia Press, Crawley, Western Australia.

Farrell, C, and Morris, J (1999) 'Professional Perceptions of Bureaucratic Change 
in the Public Sector: GPs, Headteachers and Social Workers. Public Money and Management, 19 (4).pp 31-36

Fiedler, F.E. (1967). A Theory of Leadership Effectiveness, New York: McGraw-Hill

FEFC (1997) Annual Report. Further Education Funding Council (Coventry)

Fletcher, J K (2002) The Greatly Exaggerated Demise of Heroic Leadership:

Gender, Power, and the Myth of the Female Advantage, CGO Insights, Briefing Note No. 9.

Foster, A (2005) Realising the Potential: A review of the future of Further Education colleges. DfES, London

Fox, S (2005) An Actor-Network Critique of Community in Higher Education. Studies in Higher Education 30 (1) pp $95-110$

Gleeson, D (2001) Style and Substance in Education Leadership: FE as a case in point. Journal of Education Policy 16 (3) pp $181-196$

Gleeson, D (2006) The Learning Leader in Further Education. CEL. Lancaster University.

Gleeson D, Shain, F (1999) Managing Ambiguity: between markets and manageralism - a case study of middle managers in FE. The Sociological Review 47 (3) 461-490

Gleeson, D, Davies,J, Wheeler,E (2005) On the Making and Taking of Profesionalism in the Further Education Workplace. British Journal of Sociology of Education. 26: 4. 445-460

Gleeson, D and James, D. (2007) The Paradox of Professionalism in English Further Education (forthcoming). Educational Review. Special Edition. University of Birmingham.

Gleeson, D, Knights, D (2006) Challenging Dualism: Public Professionalism in Troubled Times. Sociology. 40;2. 277-295

Grace,G (1995) School Leadership: Beyond Education Management. London. Routledge-Falmer.

Grint, K (2000) The Arts of Leadership, Oxford University Press.

Grint, K. (2005) Leadership: Limits and Possibilities, London: Palgrave

Gronn, P (2003) The New Work of Educational Leaders. Paul Chapman Press, London

Gunter H (2004) Labels and Labelling in the field of Educational Leadership. Discourse 25 (1) pp 22 42

Gunter, H. (2005)' Putting Education Back into Leadership.' Forum.47 (2-3) 181-137

Handy, C (1989) The Age of Unreason, Harmondsworth: Penguin Books.

Hendriksson, L, Wrede, S, Buran, U.(2006) Understanding Professional Projects in Welfare Service Work: Renewal of Old Professionalism. Gender, Work and Organisation, Vol 13 (2) pp 174- 192.

Hood, C and Peters, B (2004) 'The Middle Aging of New Public Management: into the Age of Paradox.' Journal of Public Administration Research and Theory 14 (3),pp 267-282

Hodge, M (1998) House of Commons Select Committee on Education and Employment (Sixth Report: Further Education, London: The Stationery Office)

Hodkinson, P, et al (2005) Transforming Learning Cultures in Further Education. ESRC Final Report (Transforming Learning Cultures in Further Education Project) www.tlrp.org 
House of Commons (2006) Securing Strategic Leadership in the Learning and Skills Sector. 25th Report of Sessions 2005 - 2006. Committee of Public Accounts. House of Commons, London

Hoyle, E and Wallace, M (2005) Educational Leadership: Ambiguity, Professionals and Managerialism, London: Sage.

Hughes, C (200) Is it possible to be a feminist manager in the 'real world of FE? Journal of Further and Higher Education 24 (2) 251-260

James, D and Diment, K (2003) 'Going Underground? Learning and Assessment in an ambiguous space.’ Journal of Vocational Education and Training, 55,4: 407-422

Kerfoot D and D. Knights (1993) 'Management, Manipulation and Masculinity: From Paternalism to Corporate Strategy in Financial Services', Journal of Management Studies, Vol. 30, No. 4, July 1993, 659-77.

Kerfoot D and D. Knights (1996) "The Best is Yet to Come?": Searching for Embodiment in Management' in D. Collinson and J. Hearn, (editors) Masculinity and Management, London: Sage, pp. 7898.

Knights, D and O'Leary, M, 'Leadership, Ethics and Responsibility to the Other, Journal of Business Ethics, 67 No. 2 August, 2006, pp. 125-137.

Knights D and Willmott, H. (1999) Management Lives!: Power and Identity in Work Organisations. Sage.

Knights, D and H. Willmott (2007) Introducing Organization Behaviour and Management, London: Thomson Learning.

Kitchener, M, Kirkpatrick,I and Whipp, R. (2000) 'Supervising Professional Work Under New Public Management: Evidence from invisible trade.’ British Journal of Management. 11 (3) 213-226

Latour, B (2005) Reassembling the Social, Oxford: Oxford University Press.

Lave, J, Wenger, E (1991) Situated Learning: Legitimate peripheral participation. Cambridge University Press, Cambridge

Leitch, S (2006) Prosperity for All in the Global Economy: World Class Skills. London HM Treasury.

Likert, R (1961) New Patterns of Management, New York: Free Press

Lucas, M (2004) Teaching in Further Education. Bedford Way Papers, Institute of Education, University of London

Lumby, J, et al (2005) Leadership, development and diversity in the learning and skills sector. Learning and Skills Research Centre (LSDA), London

LSC (2005) Learning and Skills - the Agenda for Change:the prospectus. The Learning and Skills Council . Coventry

MacDonald, J., F. S. Ravitch and P. Sumners (2005) Employment Discrimination Law: Problems, Cases and Critical Perspectives, New Jersey: Prentice Hall.

Marquand, D. (2000) 'The Rise and Fall of Civic Culture', New Statesman 13(11): 4-8.

Merrick,N (2007) Train Your Way to the Top. The Independent 11/1/07 p 10 
Miliband,D (2006). 'Public services and public goods; lessons for reform.' Speech by the Rt Hon David Miliband MP at the National School of Governace Conference, London 6 June 2006. see http:/www.defra.gov.uk/corporate/ministers/speech/david-miliband/dm060606htm Accessed July 2006.

Newman J and Nutley (20030 Transforming the Probation Service: 'What Works.' Policy and Politics 31 (4) 547-263.

Osler, A (1997) The Education \& Careers of Black Teachers: Changing identities and changing lives. Open University Press

Pearce, C. L. and Conger J (2003) 'All those years ago: The historical underpinnings of shared leadership' in Pearce, C. L. and Conger J (editors) Shared Leadership: Reframing the How's and Why's of Leadership, California: Sage Publications.

Pittinsky T. L. and Rosenthal S. A. (2005) A National Study of Confidence in Leadership, John F. Kennedy School of Government, Harvard University: Center for Public Leadership.

Pollitt, C., (2003) The Essential Public Manager. Buckingham. Open University Press.

Randle,K and Brady, N (1997) 'Managerialism and Professionalism in the Cinderella Service.' Journal of Vocational Education and Training. 49(1) 121-139.

Robson,J, Bailey,B and Larkin,S (2004) Adding Value: Investigating the Discourse of Professionalism adopted by vocational teachers. Journal of Vocational Education and Training. 17(2) 183-194

Roper, M. R. (1994) Masculinity and the British Organization Man since 1945, Oxfore: Oxford University Press.

Scott, C, Lawson, L (1997) Women at the Top in Further Education. Further Education Development Agency, London

Scase R and Goffee R (1992) Reluctant Managers: Their Work and Life Styles, London: Thomson Learning.

Selznick, P (1957) Leadership in Administration: A Sociological Interpretation, Evanston, IL: Row, Peterson.

Shain, F (2000) Managing to Lead: Women managers in the Further Education Sector. Journal of Further and Higher Education 24 (2) 217 - 230

Simkins T, Lumby, J (2002) Cultural Transformation in Further Education? Mapping the debate. Research in Post Compulsory Education 7 (1) 9-25

Simmons, R, Birchall, J, Prout, A (2006) Cultural Tensions in Public Service Delivery. Implications for Producer-Customer Relationships. Cultures of Consumption Working Paper No 26 (ESRC-AHRC Research Programme. www.consume.bbk.ac.uk).

Sinclair, A (1998) Doing Leadership Differently, Melbourne University Press.

Sinclair, A and Wilson, V (2002) new faces of leadership, Melbourne University Press.

Spillane,J (2006) Distributed Leadership. Jossey - Bass

Stodgill, R M (1974) Handbook of Leadership, New York: Free Press

Stronach,I, Corbin,B, McNamara, O,Stark,S and Warn,T (2002) Towards an Uncertain Politics of Professionalism. Journal of Education Policy. 17(1) 110-138

Whelan, L, Kerr,K, Rauch,E (2006) The preparedness of Middle Managers for Senior Roles in Scoland's Colleges. 76-94. In Collinsin,D (Ed) (2006) op cit 
Woods,P(2005) Democratic Leadership in Education. Sage.

Yukl, G (2006) Leadership in Organization, $5^{\text {th }}$ edition, New York: Prentice Hall.

Acknowledgement.

Grateful acknowledgement is expressed to the principals, senior and middle managers in the four Further Education Colleges participating in the project, and to the Centre for Excellence in Leadership Research( CEL ), at the University of Lancaster, for supporting the research. We also wish to thank David Collinson and Keith Grint for their helpful and constructive comments on an earlier version of this paper.

\section{Notes}

${ }^{1}$ Further Education Institutions are similar to Institutes of Technical and Further Education (TAFE) in Australia and, to a lesser extent, Community Colleges in North America. Different systems of FE exist in Scotland, Wales and Northern Ireland. This paper refers exclusively to the English context.

${ }^{2}$ We are aware that using the term 'practitioner' could be seen as patronising (see Collinson, 2006/7: 7) since we would rarely describe teachers in other sectors with this language. However, the term is used generically as a shorthand to encompass teachers as well as those who are administrators and managers.

${ }^{3}$ We use the term mediation here in the sense of it not only transporting meaning but also transforming it on route, and in contradiction to the term intermediation where transportation occurs without transformation. 'Their input is never a good predictor of their output; their specificity has to be taken into account every time' (Latour, 2005: 39).

${ }^{4}$ There are 385 FE colleges in England, of which 201 are general FE colleges, 98 are sixth form colleges, 50 are tertiary colleges, and the remaining 36 are specialist institutions (end of 2005/6). There are 5,371,000 learners in the FE sector as a whole (excluding those funded on Train for Gain) of which 2,841,000 are in general FE and tertiary colleges, 187,000 are in specialist colleges, 393,000 are in external institutions, 486,000 are in work-bases learning,786,000 are in personal and community development learning, 355, are in school sixth forms and 115,000 are studying FE in HE institutions. FE sector college success rates have risen by 2 percentage points since 2004/5 to 77\% in 2005/06 and so have exceeded the target of $76 \%$ set for $2007 / 08$. Of the 100 colleges inspected in $2005 / 06,11 \%$ were given an overall effectiveness rating of outstanding, $44 \%$ were good, $36 \%$ were satisfactory and $8 \%$ inadequate. Approximately 239,000 staff are employed in FE colleges in England; 44\% are fulltime and $56 \%$ are part-time. $53 \%$ are teachers, $13 \%$ are teaching support and $34 \%$ are other support. (Source FE Data and Assessment Unit.FESA division. Department for Innovation, Universities and Skills. Moorfoot. Sheffield.UK)

${ }^{5}$ Of course, the fact that the returns on training can soon evaporate though staff depletion is always the excuse for the limited resources that go into training, especially in the private sector. The alternative argument which is the raison d'ětre of education generally is that the economy and the populace benefits and that assuming a healthy circulation of labour, even organizations that lose staff they have trained can secure fully trained staff from elsewhere.

${ }^{6}$ This is an aspect of UK sex discrimination legislation that does not apply in all countries.

${ }^{7}$ This finding coincides with other research, which concludes that losing contact with students is "one of the principal reasons that teachers gave for not becoming a middle manager" (Barker, 2006/7: 105). 